\title{
S. I.: Metals in Mining Areas-Biogeochemistry, Risk and Remediation
}

\author{
Longhua $\mathrm{Wu}^{1} \cdot$ Peter Christie ${ }^{1}$
}

Received: 5 November 2021 / Accepted: 7 November 2021 / Published online: 13 November 2021

(c) The Author(s), under exclusive licence to Springer Science+Business Media, LLC, part of Springer Nature 2021

Soil pollution is a very serious environmental problem worldwide, especially in mining areas. Metal ores are essential to the development of human society and mine exploitation and smelting processes result in the release of multiple metals to their surrounding environments, notably to soils and waters. Environmental pollution is potentially harmful to human health and to ecosystem security. Taking China as an example, at 1672 soil sites in 70 mining areas surveyed, potentially toxic metals in $33.4 \%$ soil samples were over the national standard values (Ministry of Environmental Protection of the People's Republic of China, 2014). The metals released from mining solid wastes such as tailings and waste stones and acid mine drainage (AMD) are transported within and outside mining areas, resulting in various degrees of pollution of the surrounding soil environment. Furthermore, metal transfer from soils to plants and soil biota affect the soil ecosystem and potentially human health via the food chain. Studies on the characteristics, transfer and migration, risk, ecological restoration and remediation of metal pollutants in mining areas will help people to solve these pollution-related problems.

This special issue, Metals in mining areas: Biogeochemistry, Risk and Remediation, aimed to synthesize current research activities on metal biogeochemistry, environmental risk and pollution remediation. There are three sections based on the topics of the contributions: (1) the first section focuses mainly on pollution characteristics of soils and solid wastes in the areas with different types of mines, and the risk assessment of metal pollution; (2) the second section focuses on mechanisms of metal transformation in polluted soils and release from mine solid wastes, and metal accumulation and transfer to living organisms; and (3) the third section deals with novel methods and techniques for the restoration of mine sites, AMD treatments, and remediation of metal-polluted soils around mining areas.

We would like to thank Prof. Dr. Erin Bennett, the Editorin-Chief of Bulletin of Environmental Contamination and Toxicology (BECT), Prof. Dr. Huang Longbing, Prof. Dr. Guo Hongyan, Dr. Hu Wenyong, and Dr. Li Zhu, the the Guest Editors of this special issue for their kind help and supports. In addition, Dr. Pei Lei, the Associate Editor of BECT, and Dr. Guangxia Liu, the Assistant Editor of BECT, provided insightful help in realizing this effort and we thank them for their assistance. Of course, we also must thank the authors and the reviewers for their marvellous contributions.

\section{References}

Ministry of Environmental Protection of the People's Republic of China (2014) The investigation communique on national soil pollution conditions from the Ministry of Environmental Protection of the People's Republic of China and the Ministry of Land and Resources of the People's Republic of China. Beijing, China (In Chinese)

Publisher's Note Springer Nature remains neutral with regard to jurisdictional claims in published maps and institutional affiliations.
Longhua $\mathrm{Wu}$

lhwu@issas.ac.cn

1 CAS Key Laboratory of Soil Environment and Pollution Remediation, Institute of Soil Science, Chinese Academy of Sciences, Nanjing 210008, China 